\title{
Study of the Mechanisms of Vortex Variability in the Lofoten Basin Based on Energy Analysis
}

\author{
V. S. Travkin ${ }^{凶}$, T. V. Belonenko \\ Saint-Petersburg State University, Saint-Petersburg, Russian Federation \\ 凶.travkin@spbu.ru
}

Purpose. The Lofoten Basin is one of the most energetic zones of the World Ocean characterized by high activity of mesoscale eddies. The study is aimed at analyzing different components of general energy in the basin, namely the mean kinetic and vortex kinetic energy calculated using the integral of the volume of available potential and kinetic energy of the Lofoten Vortex, as well as variability of these characteristics.

Methods and Results. GLORYS12V1 reanalysis data for the period 2010-2018 were used. The mean kinetic energy and the eddy kinetic one were analyzed; and as for the Lofoten Vortex, its volume available potential and kinetic energy was studied. Mesoscale activity of eddies in winter is higher than in summer. Evolution of the available potential energy and kinetic energy of the Lofoten Vortex up to the $1000 \mathrm{~m}$ horizon was studied. It is shown that the vortex available potential energy exceeds the kinetic one by an order of magnitude, and there is a positive trend with the coefficient $0,23 \cdot 10^{15} \mathrm{~J} /$ year. It was found that in the Lofoten Basin, the intermediate layer from 600 to 900 m made the largest contribution to the potential energy, whereas the 0-400 m layer - to kinetic energy. The conversion rates of the mean kinetic energy into the vortex kinetic one, and the mean available potential energy into the vortex available potential one (baroclinic and barotropic instability) were analyzed. It is shown that the first type of transformation dominates in summer, while the second one is characterized by its increase in winter.

Conclusions. The vertical profile shows that kinetic energy of eddies in winter is higher than in summer. The available potential energy of a vortex is by an order of magnitude greater than the kinetic energy. Increase in the available potential energy is confirmed by a significant positive trend and by decrease of the vortex Burger number. The graphs of the barotropic instability conversion rate demonstrate the multidirectional flows in the vortex zone with the dipole structure observed in a winter period, and the tripole one - in summer. The barotropic instability highest intensity is observed in summer. The baroclinic instability is characterized by intensification of the regime in winter that is associated with weakening of stratification in this period owing to winter convection.

Keywords: Lofoten Basin, Norwegian Sea, available potential energy, kinetic energy, mesoscale eddies, Lofoten Vortex

Acknowledgements: the work was carried out at the financial support of the SPBU grant No. 75295423 and the RFBR grant No. 20-05-00066.

For citation: Travkin, V.S. and Belonenko, T.V., 2021. Study of the Mechanisms of Vortex Variability in the Lofoten Basin Based on Energy Analysis. Physical Oceanography, [e-journal] 28(3), pp. 294308. doi:10.22449/1573-160X-2021-3-294-308

DOI: $10.22449 / 1573-160 X-2021-3-294-308$

(C) V. S. Travkin, T. V. Belonenko, 2021

(C) Physical Oceanography, 2021

\section{Introduction}

It is generally known that climate change leads to a restructuring of the entire hydrodynamic ocean - atmosphere system and is manifested, among other things, by the strengthening of the winds and an increase in the mesoscale eddy activity of the ocean. The greatest changes are taking place in dynamically active regions.

The Lofoten Basin (LB), located in the central part of the Norwegian Sea, is rightfully called the hot spot of the North Atlantic. The LB is characterized by local 
maxima of the dispersion of the ocean level and the kinetic energy of mesoscale eddies [1-3]. Barotropic and baroclinic instabilities of the Norwegian Current generate many mesoscale eddies, which, breaking away from the current jet, move along the basin water area. The LB is not only an area of the increased mesoscale dynamics, but also a transit region through which warm and salty Atlantic waters enter the Arctic Ocean.

The LB is a topographically separate formation, as it is bounded by the Mona Ridge in the northwest and the continental slope and the Voring Plateau in the south and east (Fig. 1). The basin is surrounded by branches of the Norwegian Current: The Norwegian Atlantic Slope Current (NwASC) in its eastern part, the Norwegian Coastal Current (NCC), which extends along the Scandinavian continental slope, and the Norwegian Atlantic Front Current (NwAFC) in the west [1].

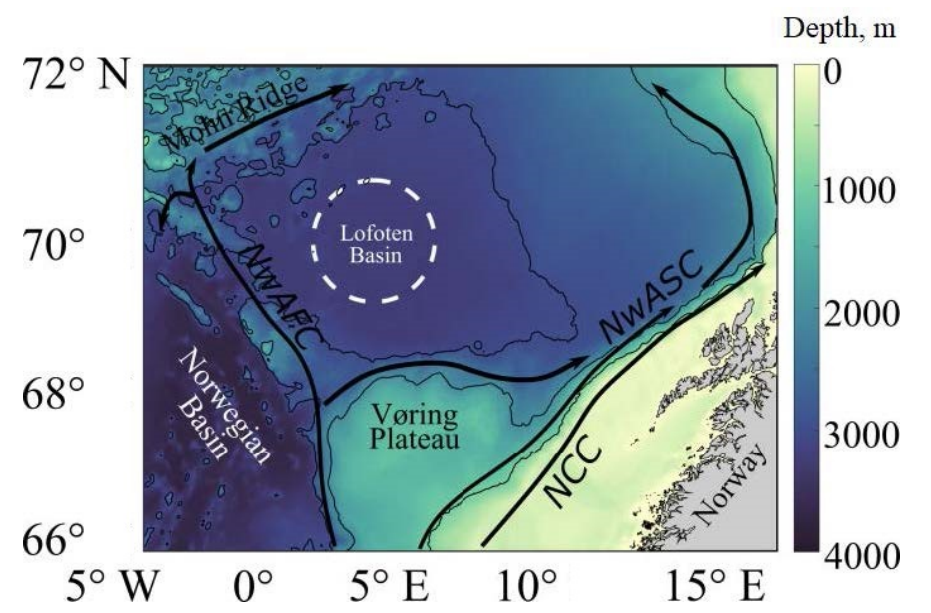

F i g. 1. Area under study. The white circle denotes the location of the anticyclonic Lofoten Vortex $(r=80 \mathrm{~km})$. Arrows indicate the main currents: NwASC, NCC, NwAFC

LB is characterized by the intense heat loss in winter $\left(\sim 80 \mathrm{~W} / \mathrm{m}^{2}\right)[4,5]$ and significant depths of the upper quasi-homogeneous layer $(0-1000 \mathrm{~m})$ during the periods of deep convection [6]. The deepening of isosteric surfaces due to the topographic features of the basin and eddy advection contribute to the long-term presence of Atlantic waters in the LB, turning it into a huge heat reservoir, which is important for the thermodynamic processes of the Arctic basin [7].

In the basin center, a quasi-permanent anticyclonic Lofoten vortex fed by mesoscale anticyclones breaking away from the Norwegian Current [8-13] is located. The core of the Lofoten vortex is characterized by extreme values of relative vorticity, approximately equal to $-0.5 f$, but sometimes reaching $-0.9 f\left(f=1.37 \cdot 10^{-4}-\right.$ is the Coriolis parameter at $\left.70^{\circ} \mathrm{N}\right)$, close to the limiting theoretical values of $f$ for anticyclones [10]. Orbital velocities reach $0.7-0.8 \mathrm{~m} \cdot \mathrm{s}^{-1}$ $[10,14]$.

In this work, the available eddy potential and kinetic energy of the Lofoten Basin is analyzed. Energy in the oceans is mainly represented by Mean Kinetic Energy (MKE), Eddy Kinetic Energy (EKE), Mean available Potential Energy (MPE) and eddy Available Potential Energy (APE). According to [15], APE is the difference 
between the total potential energy of a liquid at the moment and the potential energy of a liquid of the same mass that could exist in a similar basin after the transition to a stable reference state, when the isosteric and isobaric surfaces are at the same level. In other words, APE is that part of the potential energy of the system that can be converted into kinetic energy as a result of reversible adiabatic processes.

The total kinetic energy is usually divided into MKE and EKE. EKE is commonly used to analyze the temporal and spatial mesoscale variability of the ocean $[16,17]$.

In the LB, as in the entire World Ocean, some types of energy are transferred into others. Thus, the work of the buoyancy force is the source of the large-scale circulation APE. APE is capable of generating mesoscale eddies and, accordingly, increasing the eddy component of kinetic energy [18]. As a result, in dynamically active regions, as well as in regions of large-scale currents, transient processes dominate, with EKE exceeding MKE by an order of magnitude [18, 19].

Analyzing the relationship between eddy activity and isopycnic gradients, the authors of [20] showed that mesoscale eddies are generated by the instability in boundary currents and frontal zones of the Norwegian Sea. The authors of [10], based on the data of field measurements, found that in the core of the Lofoten Basin Eddy, the APE and EKE values are $3.4 \cdot 10^{14} \mathrm{~J}$ and $5.9 \cdot 10^{14} \mathrm{~J}$, respectively. In this case, the average eddy Burger number $\mathrm{Bu}_{\mathrm{E}}[21]$ is $1.75 \pm 0.01$. Note that these values are 10-20 times higher than the estimates obtained earlier for the Lofoten Basin Eddy [22], as well as for another mesoscale eddy - the anticyclone in the North Atlantic [23]. It should be noted that EKE and APE values below $1500 \mathrm{~m}$ horizon hardly increase, which is due to insignificant gradients of density stratification and low velocities [14].

The purpose of this work is to analyze the various components of the total energy in the LB: the average kinetic and eddy kinetic energy calculated using the integral over the volume of the available potential and kinetic energy of the Lofoten Basin Eddy, as well as the variability of these characteristics. We analyze the conversion (redistribution) of energy between the components during the period of maximum development of deep winter convection (January - March) and compare the obtained estimates with similar estimates for the summer period (June August). A deeper understanding of these processes will provide the improvement of the understanding of the basin mesoscale dynamics and the role of energy in the regeneration of the quasi-permanent Lofoten Basin Eddy.

\section{Data}

The daily data on temperature, salinity, u- and v-components of velocities obtained from the GLORYS12V1 reanalysis for 2010-2018 were used in the work. The data are available on the CMEMS (Copernicus Marine Environment Monitoring Service) portal. The GLORYS12V1 product is an eddy-resolving reanalysis of the World Ocean with $1 / 12^{\circ}$ spatial resolution at 50 horizons. The reanalysis is based on the NEMO model with ECMWF ERA-Interim forcing. GLORYS12V1 data coassimilates satellite altimetry data, sea surface temperature, sea ice concentration, and in situ temperature and salinity vertical profiles. Observations are assimilated using the Kalman filter. Temporal discreteness of data is 1 day. 


\section{Methods}

In order to calculate MKE and EKE per unit area for unit mass, the following formulas were used [2, 24]:

$$
\begin{aligned}
& \mathrm{MKE}=0,5\left(\bar{u}^{2}+\bar{v}^{2}\right), \\
& \mathrm{EKE}=0,5\left(\overline{u^{12}}+\overline{v^{12}}\right),
\end{aligned}
$$

where $\bar{u}$ and $\bar{v}$ are time-averaged velocity components; $u^{\prime}$ and $v^{\prime}$ are the anomalies of velocity components calculated for each grid point and further averaged over the time:

$$
\begin{aligned}
& u^{\prime}=u-\bar{u}, \\
& v^{\prime}=v-\bar{v} .
\end{aligned}
$$

Averaging period is 2010-2018.

For the region of the Lofoten Basin Eddy bounded by a radius of $R=80 \mathrm{~km}$ (white circle in Fig. 1), one can calculate the volumetric values of the Available Potential Energy $\left(\mathrm{APE}_{\mathrm{V}}\right)$ and Eddy Kinetic Energy (KE) (by volumetric values we mean the values calculated using the integral over the volume) by the following formulas [23, 25]:

$$
\begin{aligned}
& \operatorname{APE}_{\mathrm{V}}=\pi \int_{0}^{R} \int_{-H}^{0} g z\left[\rho_{r e f}(z)-\rho(r, z)\right] r d r d z, \\
& \mathrm{KE}=0.5 \pi \int_{0}^{R} \int_{-H}^{0} \rho(r, z) U(r, z)^{2} r d r d z,
\end{aligned}
$$

where $H$ is the maximum depth (in the calculations assumed to be equal to $1000 \mathrm{~m}$ ); $\rho_{\text {ref }}$ is an average potential density profile outside the eddy region $(r>80 \mathrm{~km})$. Formulas (2) are written under the assumption that the eddy is radially symmetric. The eddy Burger number was calculated by the formula [21, 23]

$$
\mathrm{Bu}_{\mathrm{E}}=\mathrm{KE} / \mathrm{APE}_{\mathrm{V}} \cdot
$$

It is known that the flux of disturbances can extract energy from the average flux through the instabilities [26]. In order to study the contribution of various sources to eddy energy, the indicators of the energy conversion rate are introduced: $\mathrm{BC}$ and BT. BC characterizes the rate of MPE conversion into APE, which is one of the sources of mesoscale eddies, while BT characterizes the rate of MKE conversion into EKE. In other words, BT is the coefficient of barotropic transformation, which, if positive, transforms the energy of average horizontal shears and transfers it to the eddy field; BC is the baroclinic transformation coefficient, which, if positive, redistributes energy from the MPE field (i.e., horizontal density gradients) into the eddy field. Thus, the source of EKE is the baroclinic instability of fluxes (BC), in 
which the generation of EKE occurs due to MPE (MPE $\rightarrow$ APE $\rightarrow$ EKE) and barotropic instability (BT) formed due to MKE: MKE $\rightarrow$ EKE [27].

We used the following formulas for the calculations [27-29]:

$$
\begin{aligned}
& \mathrm{BC}=-\frac{g^{2}}{\overline{N^{2}} \rho_{0}}\left(\overline{u^{\prime}} \rho^{\prime} \frac{\partial \bar{\rho}}{\partial x}+\overline{v^{\prime}} \rho^{\prime} \frac{\partial \bar{\rho}}{\partial y}\right), \\
& \mathrm{BT}=-\rho_{0}\left[\overline{u^{\prime}} \frac{\partial \bar{u}}{\partial x}+\overline{v^{\prime}} \frac{\partial \bar{v}}{\partial y}+\overline{u^{\prime} v^{\prime}}\left(\frac{\partial \bar{v}}{\partial x}+\frac{\partial \bar{u}}{\partial y}\right)\right],
\end{aligned}
$$

where $\mathrm{g}$ is a free fall acceleration; $\rho_{0}$ is a background density of the seawater; $N$ is a buoyancy frequency.

\section{Results}

Now we are to consider the kinetic energy spatial distribution in the basin (Fig. 2). The energy is calculated by the formulas (1). In Fig. 2, $a$ it can be seen that the maximum EKE values are observed in the region of the Lofoten Basin Eddy core location (up to $250 \mathrm{~cm}^{2} \cdot \mathrm{s}^{-2}$ ). In addition, kinetic energy maxima (up to 100$130 \mathrm{~cm}^{2} \cdot \mathrm{s}^{-2}$ ) are noted in the LB northwestern and eastern parts and on the continental slope of Norway, while for the rest of the water area the EKE values do not exceed $50 \mathrm{~cm}^{2} \cdot \mathrm{s}^{-2}$.

The MKE, in comparison with the EKE, is characterized by lower values (Fig. 2, b). Although the maximum MKE values were also recorded in the area of the Lofoten Basin Eddy, they are lower than the corresponding EKE values. Note that if the EKE maxima (Fig. 2, a) correspond to the central part of the Lofoten Basin Eddy (the center is located approximately at $69.8^{\circ} \mathrm{N}, 4.8^{\circ} \mathrm{E}$ ), then in the MKE distribution (Fig. 2 , b) this region corresponds to the minimum values close to zero, and the increased MKE values are located at the eddy periphery. Another feature is the topography study of the increased MKE values: in Fig. 2, b it can be seen that the elongated regions of increased values are located along the isobaths. Obviously, this dependence repeats the location features of the main jets of the Norwegian Slope and Norwegian Frontal currents (see Fig. 1).

The difference between the EKE and MKE is positive over most of the LB, with the largest values recorded in the core of the Lofoten Basin Eddy, as well as in the central and eastern parts of the basin (Fig. 2, c). While at the periphery of the Lofoten Basin Eddy, which is characterized by high MKE values, the difference is negative, in the area of the Voring plateau and in the western part of the LB it is close to zero (see also [30]). 

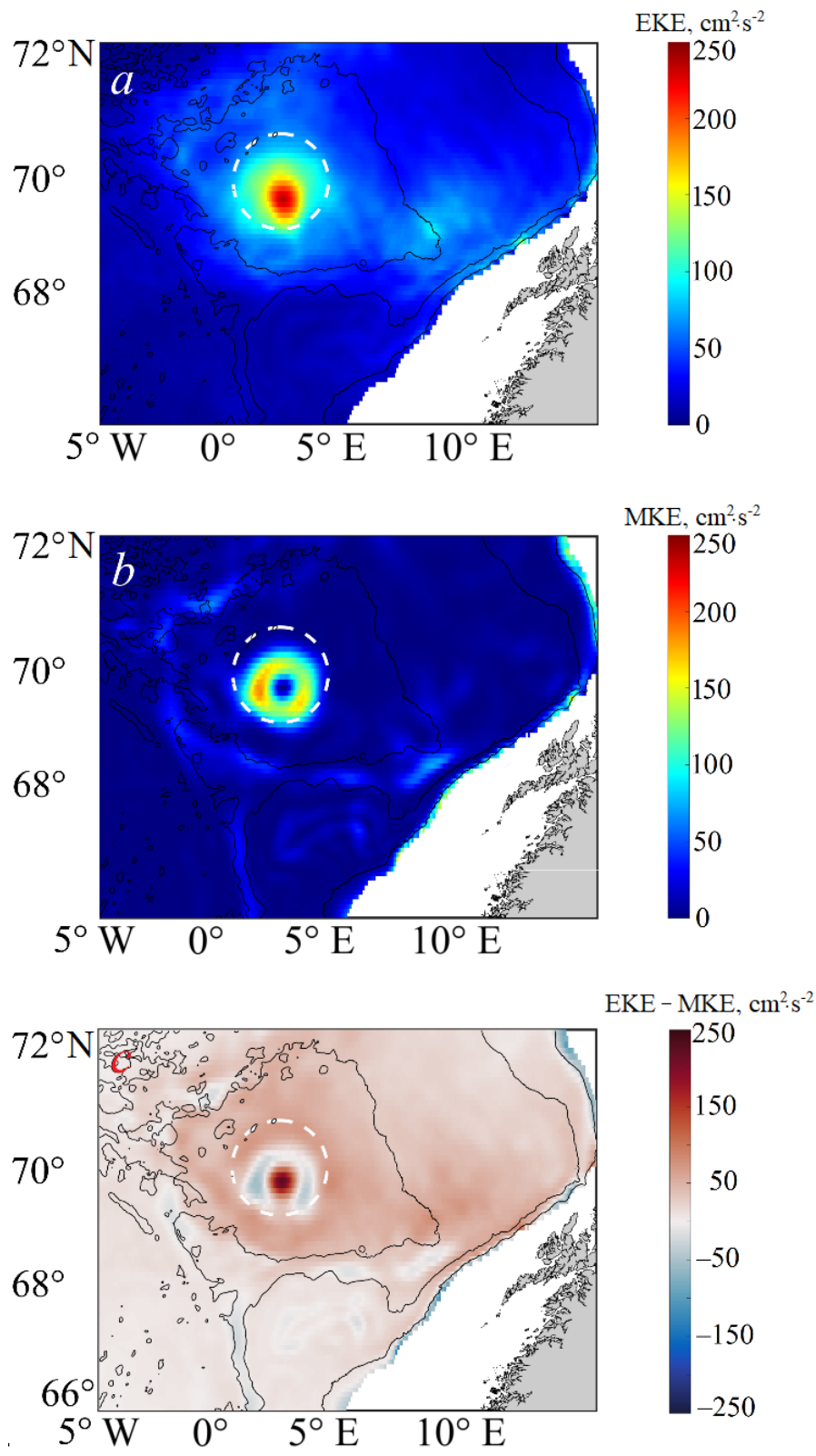

F i g. 2. Spatial distribution at the $500 \mathrm{~m}$ horizon: $a$ - EKE; $b$ - MKE; $c$ - difference between EKE and MKE. Averaging is for the period 2010-2018. Black lines show the 1000, 2000 and $3000 \mathrm{~m}$ isobaths

Vertical distribution of these characteristics is shown in Fig. 3. The values were averaged separately for the winter and summer periods: January - March (Fig. 3, a) and June - August (Fig. 3, $b$ ). It was found that the EKE dominates at all depths down to $1000 \mathrm{~m}$. This feature is most clearly observed in the intermediate layer from 100 to $500 \mathrm{~m}$, where the difference is the greatest. Seasonal variability, leading to an increase in kinetic energy in winter compared to summer, is also noted. 


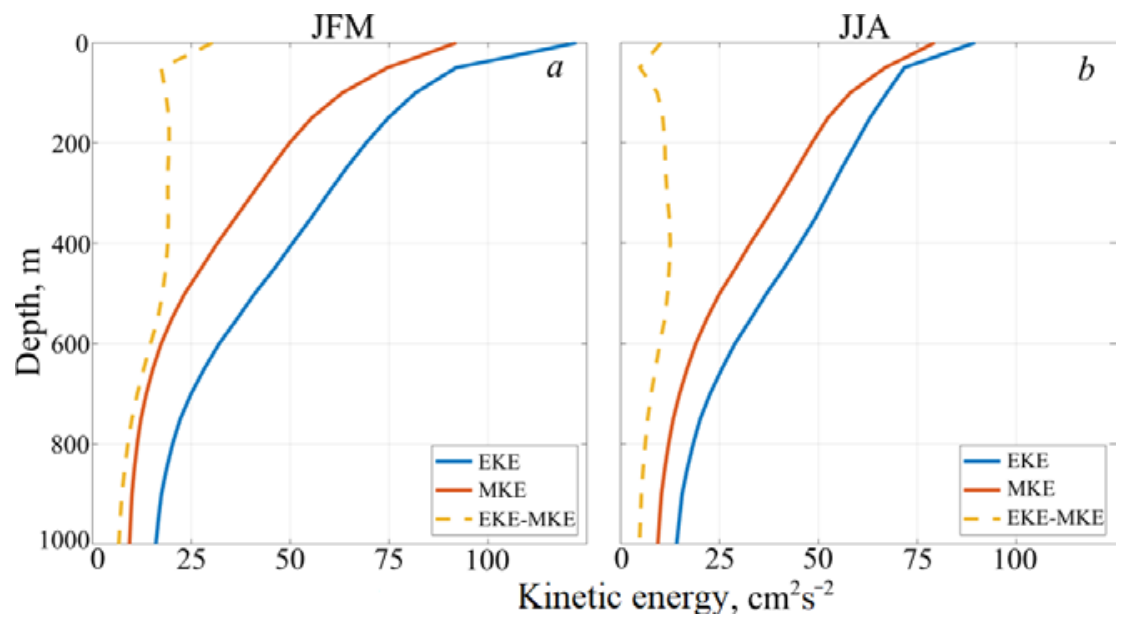

F i g. 3. Vertical profiles of the long-term values of EKE (blue line), MKE (red line) and their differences (EKE - MKE) (yellow line): $a$ - January - March (JFM); $b$ - June - August (JJA)
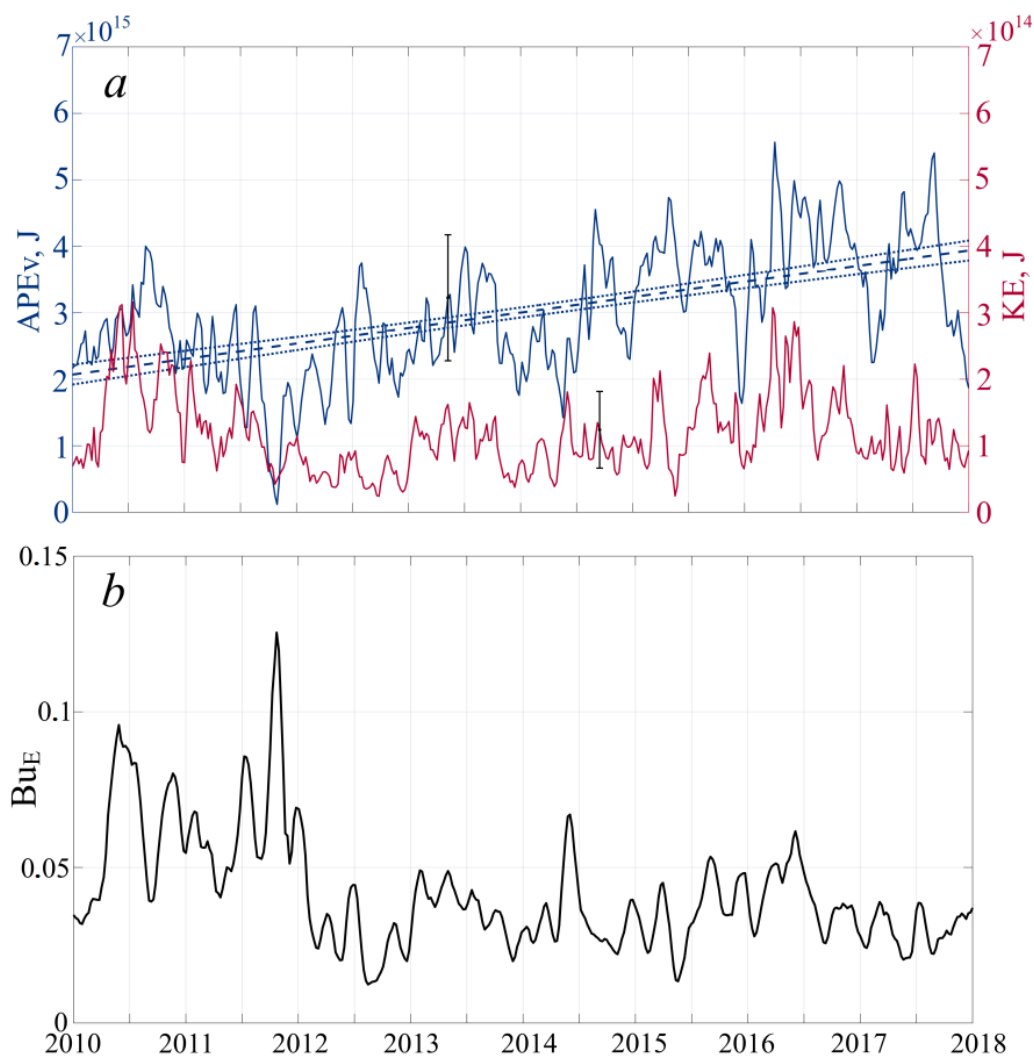

F i g. 4. Time variation of (APEv) (blue line) and (KE) (red line), and linear trend of APEv (blue dotted line) with the confidence intervals (blue dotted lines) (a); evolution of the vortex Burger number $(b)$ 
The evolution of the volumetric values of the Available Potential Energy and kinetic energy for the Lofoten Basin Eddy is shown in Fig. 4, $a$, and the evolution of the Burger number is shown in Fig. $4, b$. It can be seen that the evolution is accompanied by a positive significant trend, while this trend is absent for KE. The increase in $\mathrm{APE}_{\mathrm{V}}$ values is possibly due to the deepening of isosteric surfaces in the LB in connection with the ongoing climatic processes in the North Atlantic (see [7]).

The obtained estimates of $\mathrm{APE}_{\mathrm{V}}$ and $\mathrm{KE}$ are generally quite similar to the values presented in earlier studies [22, 23]. Thus, the Lofoten Basin Eddy is characterized by a predominance $\mathrm{APE}_{\mathrm{V}}$ (from $0.1 \cdot 10^{15}$ to $5.5 \cdot 10^{15} \mathrm{~J}$ ) over $\mathrm{KE}$ (from $0.2 \cdot 10^{14}$ to 3.0.10 14 J) (Fig. 4, a), which leads to $\mathrm{Bu}_{\mathrm{E}}$ values equal to $\sim 0.02-0.13$ (Fig. 4, $b$ ). In addition, a significant positive trend for $\mathrm{APE}_{\mathrm{V}}$ equal to $0.23 \cdot 10^{15} \mathrm{~J} / \mathrm{year}$ (Fig. 4, a), which is reflected in a decrease in the Burger's vortex number (Fig. 4, b), was recorded.

In Fig. 5 the vertical profiles of $\mathrm{APE}_{\mathrm{V}}, \mathrm{KE}$ and $\mathrm{Bu}_{\mathrm{E}}$, plotted with weekly averaging (thin lines), as well as averaged over 2010-2018 values (thick lines), are represented. It can be seen that $\mathrm{APE}_{\mathrm{V}}$ also has negative values at the depths from 0 to $400 \mathrm{~m}$ (Fig. 5, a). This indicates that the water masses in the Lofoten Basin Eddy are denser in comparison with the surrounding waters outside the eddy (Fig. 5, a). The fastest variation in the APEV is recorded at intermediate depths of 200-800 m. Thus, the maximum average value was recorded at the $700 \mathrm{~m}$ horizon, which demonstrates the presence of the highest density gradients here, due to the displacement of isopycnic lines. The maximum $\mathrm{APE}_{\mathrm{V}}$ values are observed in the intermediate layer from 600 to $900 \mathrm{~m}$.

On the vertical profiles of $\mathrm{KE}$, the values are positive and are characterized by a gradual decrease in values with depth (Fig. 5, b). The largest individual maximum values are also recorded in the surface layer down to $300 \mathrm{~m}$ depth. Further, at the depths from $400 \mathrm{~m}$ to $750 \mathrm{~m}$, the KE decreases on individual profiles and its average values.
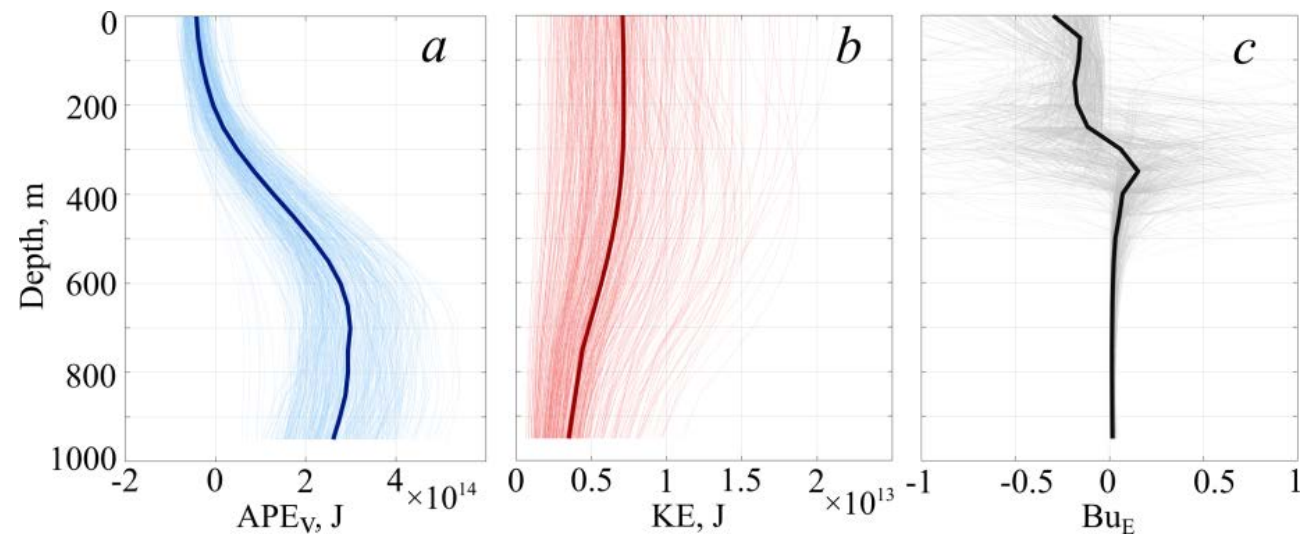

F i g. 5. Vertical profiles (thin lines) of $\operatorname{APEV}_{(}(a), \mathrm{KE}(b)$ and the vortex Burger number $\mathrm{Bu}_{E}(c)$ in the Lofoten Vortex. The average of each value is indicated by a thick line 
In Fig. 5, $c$ the vertical variability of Burger number $\mathrm{Bu}_{\mathrm{E}}$ calculated for individual profiles and in averaging. It can be seen that the extreme values for individual profiles (exceeding 1.75 in modulus) were recorded in the upper layer of the sea from the surface and down to $500 \mathrm{~m}$. The maximum gradients are typical for the core of the Lofoten Basin Eddy (300-400 m).

The BT and BC energy conversion graphs, which characterize the conversion between different components of the total energy, are of the greatest interest. In Fig. 6 the rate of converting the MKE to EKE is represented. Positive values indicate the transition of the Average Kinetic Energy into the eddy one, while negative values indicate the energy flux in the opposite direction. It can be seen that the most energetic transformation zones are still the Lofoten Basin Eddy area and the core of the Norwegian Slope Current.

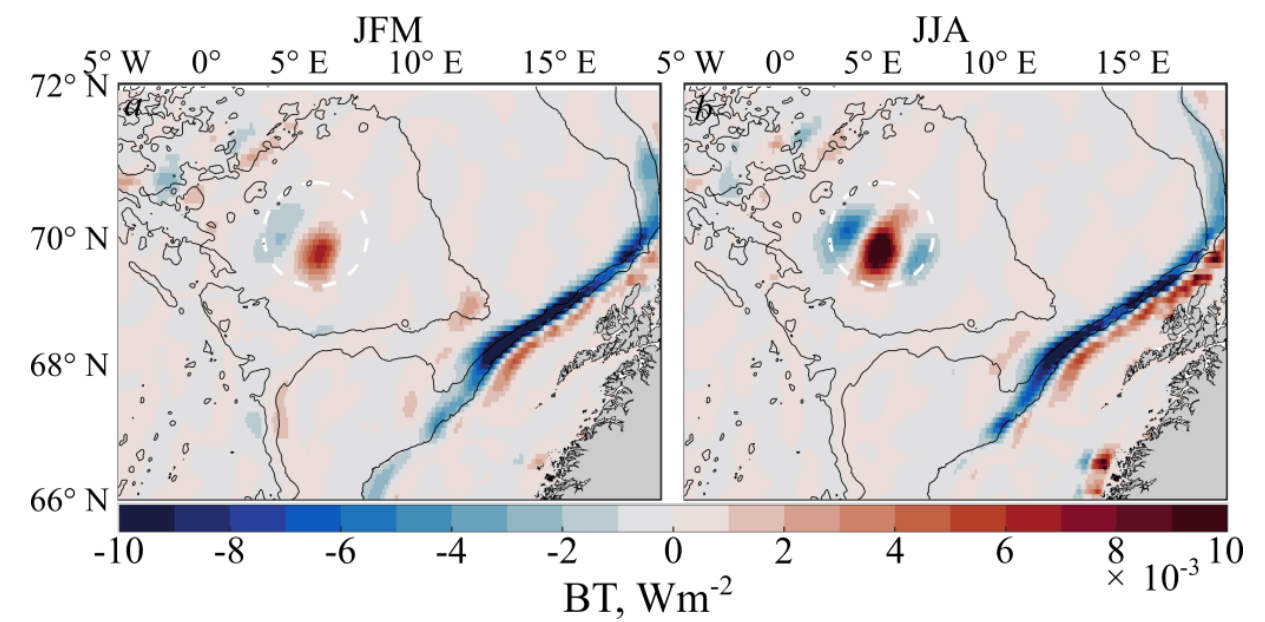

F i g. 6. Spatial distribution of BT (conversion of MKE into EKE) integrated in the upper $500 \mathrm{~m}$ sea layer for the periods: $a$ - January - March (JFM); $b$ - June - August (JJA). Black lines show the 1000, 2000 and $3000 \mathrm{~m}$ isobaths

Note that in the area where the Lofoten Basin Eddy is located, multidirectional fluxes are observed in different parts of the eddy. The alternation of red and blue regions in the Lofoten Basin Eddy zone demonstrates an active return of the Eddy Kinetic Energy to the mean field, and vice versa. In winter, in the northwestern part of the eddy, an area of negative values (blue), and on the opposite side - positive (red) is observed.

The Lofoten Basin Eddy core is characterized by positive values of the MKE and the energy flux from its mean field in the EKE. Obviously, this fact characterizes the eddy stability and its constant presence in this region.

In the summer period, two areas of negative values, located in the northwestern and southeastern periphery of the eddy, where the transformation of EKE into MKE takes place, are observed. In [31], a similar alternation of regions of positive and negative vertical velocities in the Lofoten Basin Eddy is analyzed. The authors associate this feature with the influence of the Norwegian Slope Current, which propagates in the eddy water area northwestwards. It is possible that the symmetrical arrangement of the regions of multidirectional energy fluxes is also due to the flux 
influence. Note also that energy conversion is more intense in the summer than in the winter months.

Another energetic region in Fig. 6 is an area of the Norwegian Slope Current, where energy is also redistributed from one form to another. The area in which the Norwegian Slope Current core is located is characterized by negative BT values in its western periphery and positive in the eastern one. A detailed analysis of this phenomenon is presented in [32].

Separate local extrema of BT are also observed in the regions of the Voring plateau and the northwestern part of the basin, but their values are significantly lower.

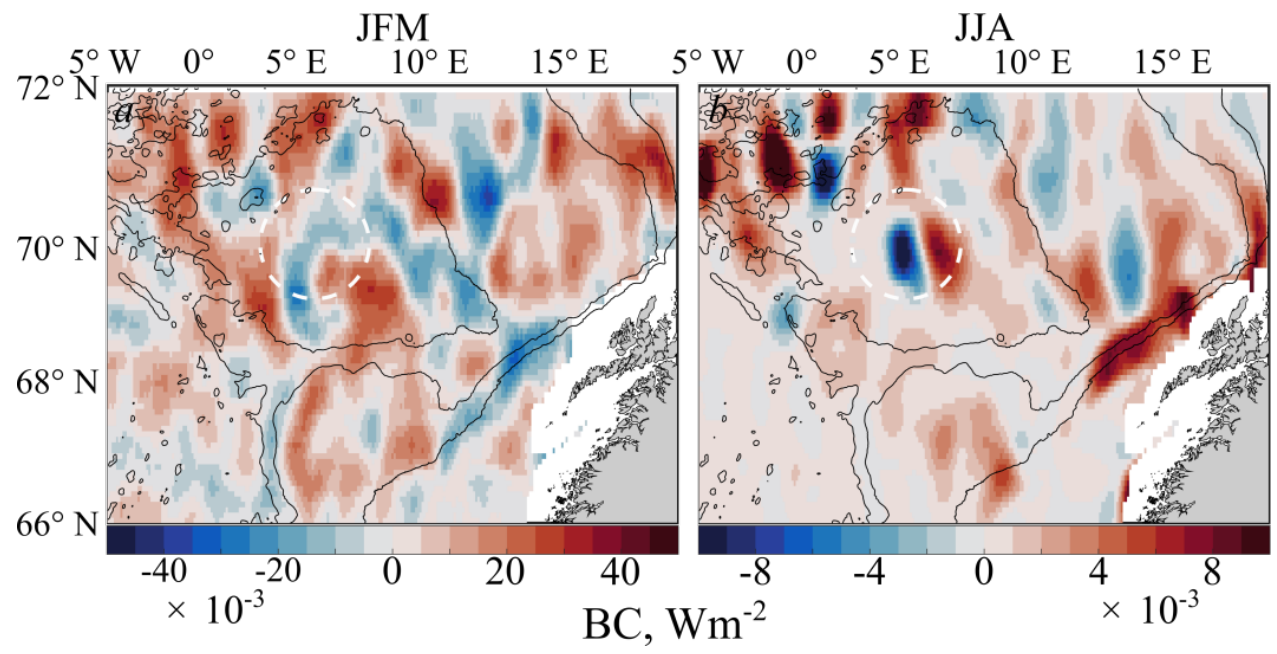

F i g. 7. Spatial distribution of BC (conversion of MPE into APE) integrated in the upper $500 \mathrm{~m}$ sea layer for the periods: $a$ - January - March (JFM); $b$ - June - August (JJA). Black lines show the 1000, 2000 and $3000 \mathrm{~m}$ isobaths

In Fig. 7 shows the rate of MPE conversion into APE is represented. Positive $B C$ values indicate the conversion from MPE to APE, while negative values indicate the conversion from APE to MPE. Note that in winter, the BC values are more than four times higher than the corresponding values for the summer period. Obviously, this is primarily due to the weak stratification of the upper layers and low $N^{2}$ values in winter due to the formation of a thick quasi-homogeneous layer.

The most active transformation zones are the central and eastern LB parts of the, as well as the continental slope of Norway. It is surprising that these processes are very little expressed in the adjacent area of the Norwegian Basin (Fig. 7). It should be noted that in the winter period in the LB water area, the areas with a predominance of positive BC values are formed, and on the continental slope of Norway, an area of negative $\mathrm{BC}$ values is formed along the isobaths, while in summer, a little to the north, the energy is transformed in the opposite direction with an increase in APE. 


\section{Conclusions}

Based on GLORYS12V1 data for 2010-2018, the mean and eddy kinetic energies were analyzed, as well as the available volumetric potential and volumetric kinetic energy of a quasi-constant eddy. For the first time, vertical profiles of volumetric values of $\mathrm{APEv}_{\mathrm{v}}$ and KE were obtained in the Lofoten Basin Eddy. The work presents spatial distributions, as well as vertical profiles of the considered characteristics. Estimates of the vortex Burger number are obtained.

It is demonstrated that the Lofoten Basin Eddy core is characterized by increased (relative to the average values) values of the eddy kinetic energy. However, at the eddy periphery, on the contrary, the average values of kinetic energy dominate.

The kinetic energy vertical profiles demonstrate an increase in the mesoscale activity of eddies in winter compared to summer, while the eddy component still dominates.

The evolution of the Lofoten Basin Eddy available potential and kinetic energy, calculated in the layer from the surface down to $1000 \mathrm{~m}$, is studied. It is shown that the available potential energy of the eddy is an order of magnitude higher than the kinetic energy, and demonstrates a positive trend. An increase in the available potential energy during 2010-2018 is confirmed by a significant trend with a coefficient of $0.23 \cdot 10^{15} \mathrm{~J} /$ year, which reflects the deepening of the isopycnic surfaces, which, in turn, may be associated with climatic changes in the North Atlantic. An increase in the values of the available potential energy is accompanied by a decrease in the Burger's vortex number.

On the vertical profiles of the Lofoten Basin Eddy available potential energy, one can see negative values in the surface layer down to $300 \mathrm{~m}$ depth. The maximum $\mathrm{APE}_{\mathrm{V}}$ values are recorded at $700 \mathrm{~m}$ horizon, while the largest contribution to the potential energy is made by the intermediate layer from 600 to $900 \mathrm{~m}$. KE is characterized by the distribution of maximum values in a quasi-homogeneous layer from the surface down to $300 \mathrm{~m}$, but further with an increase in depth, KE starts to decrease slowly, accelerating the decline after $750 \mathrm{~m}$ horizon. Thus, the layer from 0 to $400 \mathrm{~m}$ makes the greatest contribution to the kinetic energy in the LB.

The vertical profile of the vortex number $\mathrm{Bu}_{E}$ demonstrates the inhomogeneity of values in the layer from 0 to $400 \mathrm{~m}$, caused by negative and close to zero $\mathrm{APE}_{\mathrm{V}}$ values, as well as an increase in $\mathrm{KE}$ in the surface layer. The extreme Burger values for individual profiles reach 1.75 .

The $B T$ conversion rate graphs (barotropic instability: MKE $\rightarrow$ EKE) indicate the presence of multidirectional fluxes in the eddy zone. Note that a dipole structure is observed in winter and a tripole structure in summer, and in the Lofoten Basin Eddy zone these fluxes are more intense in summer. The area where the Norwegian Slope Current core is located is characterized by negative BT in the west and positive in the east in both seasons.

In contrast to the $\mathrm{BT}$, the $\mathrm{BC}$ (baroclinic instability: MPE $\rightarrow \mathrm{APE}$ ) is characterized by an increase in fluxes in winter, which is related to a stratification weakening during this period due to winter convection. During this period, the areas with a predominance of positive $\mathrm{BC}$ values are formed in the $\mathrm{LB}$ water area. On the continental slope of Norway, an area of negative BC values stretched along the 
isobaths is formed, and in the summer period a transformation of energy in the opposite direction takes place a little further north. In winter, the baroclinic instability dominates, the BC values are 2-3 times higher than BT maximum values, and in winter baroclinic instability is observed throughout the entire water area of the basin, while increased BT values are characteristic only for the Lofoten Basin Eddy region and in magnitude they are significantly inferior to the BC values. However, in summer the barotropic fluxes and BT values exceed the corresponding $\mathrm{BC}$ values.

Materials and some figures were published in abridged form in the presentation of reports at conferences ${ }^{1}$.

\footnotetext{
${ }^{1}$ Travkin, V.S. and Belonenko, T.V., 2020. [Kinetic and Potential Energy of the Lofoten Basin Eddies According to Satellite and In Situ Data]. In: IKI RAS, 2020. [Materials of the 18th All-Russian Open Conference "Modern Problems of Remote Sensing of the Earth from Space"]. Moscow: IKI RAN, p. 182. doi:10.21046/18DZZconf-2020a; Travkin, V.S. and Belonenko, T.V., 2021. [Kinetic and Potential Energy of Currents in the Lofoten Basin Area]. In: IO RAS, 2021. [Materials of the VI AllRussian Conference of Young Scientists "Integrated Research of the World Ocean" (KIMO)]. Moscow (in print); Travkin, V.S. and Belonenko, T.V., 2020. [Kinetic and Potential Energy of the Lofoten Basin Based on the Satellite Data]. In: MGO 2020 named after L. N. Karlin, 2020. [Proceedings of the IV AllRussian Conference and Exhibition "Hydrometeorology and Ecology: Achievements and Development Prospects"]. Saint Petersburg: Khimizdat, pp. 350-352. Available at: http://mgospb.ru/f/sbornik_trudy_konferencii_2020.pdf [Accessed: 30 April 2021] (in Russian).
}

\section{REFERENCES}

1. Volkov, D.L., Belonenko, T.V. and Foux, V.R., 2013. Puzzling over the Dynamics of the Lofoten Basin - a Sub-Arctic Hot Spot of Ocean Variability. Geophysical Research Letters, 40(4), pp. 738-743. http://dx.doi.org/10.1002/grl.50126

2. Volkov, D.L., Kubryakov, A.A. and Lumpkin, R., 2015. Formation and variability of the Lofoten Basin Vortex in a High-Resolution Ocean Model. Deep Sea Research Part I: $\begin{array}{llll}\text { Oceanographic Research Papers, 105, pp. } & \text { 142-157. }\end{array}$ https://doi.org/10.1016/j.dsr.2015.09.001

3. Belonenko, T.V., Volkov, D.L., Norden, Y.E. and Ozhigin, V.K., 2014. Water Circulation in the Lofoten Basin of the Norwegian Sea. Vestnik of Saint Petersburg University. Earth Sciences, (2), pp. 108-121 (in Russian).

4. Isachsen, P.E., LaCasce, J.H. and Pedlosky, J., 2007. Rossby Wave Instability and Apparent Phase Speeds in Large Ocean Basins. Journal of Physical Oceanography, 37(5), pp. 1177-1191. https://doi.org/10.1175/JPO3054.1

5. Nilsen, J.E. and Falck, E., 2006. Variations of mixed layer properties in the Norwegian Sea for the period 1948-1999. Progress in Oceanography, 70(1), pp. 58-90. https://doi.org/10.1016/j.pocean.2006.03.014

6. Fedorov, A.M., Bashmachnikov, I.L. and Belonenko, T.V., 2019. Winter Convection in the Lofoten Basin according to ARGO Buoys and Hydrodynamic Modeling. Vestnik of Saint Petersburg University. Earth Sciences, 64(3), pp. 491-511. doi:10.21638/spbu07.2019.308 (in Russian).

7. Novoselova, E.V. and Belonenko, T.V., 2020. Isopycnal Advection in the Lofoten Basin of the Norwegian Sea. Fundamentalnaya i Prikladnaya Gidrofizika, 13(3), pp. 56-67. doi:10.7868/S2073667320030041 (in Russian). 
8. Zinchenko, V.A., Gordeeva, S.M., Sobko, Yu.V. and Belonenko, T.V., 2019. Analysis of Mesoscale Eddies in the Lofoten Basin Based on Satellite Altimetry. Fundamentalnaya $i$ Prikladnaya Gidrofizika, 12(3), pp. 46-54. doi:10.7868/S2073667319030067 (in Russian).

9. Gordeeva, S., Zinchenko, V., Koldunov, A., Raj, R.P. and Belonenko, T.V. 2020. Statistical Analysis of Long-Lived Mesoscale Eddies in the Lofoten Basin from Satellite Altimetry. Advances in Space Research, 68(2), pp. 364-377. https://doi.org/10.1016/j.asr.2020.05.043

10. Fer, I., Bosse, A., Ferron, B. and Bouruet-Aubertot, P., 2018. The Dissipation of Kinetic Energy in the Lofoten Basin Eddy. Journal of Physical Oceanography, 48(6), pp. 1299-1316. doi:10.1175/JPO-D-17-0244.1

11. Belonenko, T.V., Bashmachnikov, I.L., Koldunov, A.V. and Kuibin, P.A., 2017. On the Vertical Velocity Component in the Mesoscale Lofoten Vortex of the Norwegian Sea. Izvestiya, Atmospheric and Oceanic Physics, 53(6), pp. 641-649. doi:10.1134/S0001433817060032 (in Russian).

12. Travkin, V.S. and Belonenko, T.V., 2019. Seasonal Variability of Mesoscale Eddies of the Lofoten Basin Using Satellite and Model Data. Russian Journal of Earth Sciences, 19(5), ES5004. doi:10.2205/2019ES000676

13. Sandalyuk, N.V., Bosse, A. and Belonenko, T.V., 2020. The 3-D Structure of Mesoscale Eddies in the Lofoten Basin of the Norwegian Sea: A Composite Analysis from Altimetry and In Situ Data. Journal of Geophysical Research: Oceans, 125(10), e2020JC016331. doi:10.1029/2020JC016331

14. Bosse, A., Fer, I., Lilly, J.M. and Søiland, H., 2019. Dynamical Controls on the Longevity of a Non-Linear Vortex: The Case of the Lofoten Basin Eddy. Scientific Reports, 9, 13448. https://doi.org/10.1038/s41598-019-49599-8

15. Reid, R.O., Elliott, B.A. and Olson, D.B., 1981. Available Potential Energy: A Clarification. Journal of Physical Oceanography, 11(1), pp. 15-29. https://doi.org/10.1175/15200485(1981)011<0015:APEAC>2.0.CO;2

16. White, M.A. and Heywood, K.J., 1995. Seasonal and Interannual Changes in the North Atlantic Subpolar Gyre from Geosat and TOPEX/POSEIDON Altimetry. Journal of Geophysical Research: Oceans, 100(C12), pp. 24931-24941. doi:10.1029/95JC02123

17. Kang, D. and Curchitser, E.N., 2017. On the Evaluation of Seasonal Variability of the Ocean Kinetic Energy. Journal of Physical Oceanography, 47(7), pp. 1675-1683. doi:10.1175/JPOD-17-0063.1

18. Gill, A.E., Green, J.S.A. and Simmons, A.J., 1974. Energy Partition in the Large-Scale Ocean Circulation and the Production of Mid-Ocean Eddies. Deep Sea Research and Oceanographic Abstracts, 21(7), pp. 499-528. https://doi.org/10.1016/0011-7471(74)90010-2

19. Chelton, D.B., Gaube, P., Schlax, M.G., Early, J.J. and Samelson, R.M., 2011. The Influence of Nonlinear Mesoscale Eddies on Near-Surface Oceanic Chlorophyll. Science, 334(6054), pp. 328-332. doi:10.1126/science.1208897

20. Trodahl, M. and Isachsen, P.E., 2018. Topographic Influence on Baroclinic Instability and the Mesoscale Eddy Field in the Northern North Atlantic Ocean and the Nordic Seas. Journal of Physical Oceanography, 48(11), pp. 2593-2607. doi:10.1175/JPO-D-17-0220.1

21. D’Asaro, E.A., 1988. Observations of Small Eddies in the Beaufort Sea. Journal of Geophysical Research: Oceans, 93(C6), pp. 6669-6684. https://doi.org/10.1029/JC093iC06p06669

22. Søiland, H., Chafik, L. and Rossby, T., 2016. On the Long-Term Stability of the Lofoten Basin Eddy. Journal of Geophysical Research: Oceans, 121(7), pp. 4438-4449. https://doi.org/10.1002/2016JC011726 
23. Fernández-Castro, B., Evans, D.G., Frajka-Williams, E., Vic, C. and Naveira-Garabato, A.C., 2020. Breaking of Internal Waves and Turbulent Dissipation in an Anticyclonic Mode Water Eddy. Journal of Physical Oceanography, 50(7), pp. 1893-1914. doi:10.1175/JPO-D-190168.1

24. Martínez-Moreno, J., Hogg, A.M., Kiss, A.E., Constantinou, N.C. and Morrison, A.K., 2019. Kinetic Energy of Eddy-Like Features from Sea Surface Altimetry. Journal of Advances in Modeling Earth Systems, 11(10), pp. 3090-3105. https://doi.org/10.1029/2019MS001769

25. Hebert, D., 1988. The Available Potential Energy of an Isolated Feature. Journal of Geophysical Research: Oceans, 93(C1), pp. 556-564. https://doi.org/10.1029/JC093iC01p00556

26. Pedlosky, J., 1987. Geophysical Fluid Dynamics. New York: Springer, 710 p. doi:10.1007/9781-4612-4650-3

27. Xu, A., Yu, F., Nan, F. and Ren, Q., 2020. Characteristics of Subsurface Mesoscale Eddies in the Northwestern Tropical Pacific Ocean from an Eddy-Resolving Model. Journal of Oceanology and Limnology, 38(5), pp. 1421-1434. https://doi.org/10.1007/s00343-0209313-4

28. Eden, C. and Böning, C., 2002. Sources of Eddy Kinetic Energy in the Labrador Sea. Journal of Physical Oceanography, 32(12), pp. 3346-3363. doi:10.1175/15200485(2002)032<3346:SOEKEI>2.0.CO;2

29. Zhan, P., Subramanian, A.C., Yao, F., Kartadikaria, A.R., Guo, D. and Hoteit, I., 2016. The Eddy Kinetic Energy Budget in the Red Sea. Journal of Geophysical Research: Oceans, 121(7), pp. 4732-4747. doi:10.1002/2015JC011589

30. Fedorov, A.M. and Belonenko, T.V., 2020. Interaction of Mesoscale Vortices in the Lofoten Basin Based on the GLORYS Database. Russian Journal of Earth Sciences, 20(2), ES2002. doi:10.2205/2020ES000694

31. Koldunov, A.V. and Belonenko, T.V., 2020. Hydrodynamic Modeling of Vertical Velocities in the Lofoten Vortex. Izvestiya, Atmospheric and Oceanic Physics, 56(5), pp. 502-511. https://doi.org/10.1134/S0001433820040040

32. Raj, R.P., Halo, I., Chatterjee, S., Belonenko, T., Bakhoday-Paskyabi, M., Bashmachnikov, I., Fedorov, A. and Xie, J., 2020. Interaction between Mesoscale Eddies and the Gyre Circulation in the Lofoten Basin. Journal of Geophysical Research: Oceans, 125(7), e2020JC016102. https://doi.org/10.1029/2020JC016102

About the authors:

Vladimir S. Travkin, Research Engineer, Oceanology Department, Saint-Petersburg State University (7-9 Universitetskaya nab., St. Petersburg, 199034, Russia), v.travkin@spbu.ru

Tat'yana V. Belonenko, Professor, Oceanology Department, Saint-Petersburg State University (7-9 Universitetskaya nab., St. Petersburg, 199034, Russia), Dr. Sci. (Geogr.), ORCID ID: 0000-00034608-7781, WoS ResearcherID: K-2162-2013, Scopus Author ID: 6507005889, t.v.belonenko@spbu.ru

Contribution of the co-authors:

Vladimir S. Travkin - analysis of literature data, participation in the development of methods, analysis of the obtained data, preparation of graphic material, and the main text of the paper 
Tat'yana V. Belonenko - problem statement, formulation of purposes and objectives of the study, development of approaches to the analysis, participation in writing and editing the text of the paper

All the authors have read and approved the final manuscript.

The authors declare that they have no conflict of interest. 